\title{
RANCANG BANGUN SISTEM PERINGATAN DINI BAHAYA TANAH LONGSOR DENGAN SENSOR HYGROMETER DAN PIEZOELECTRIC
}

\author{
Ni Kadek Diah Parwati ${ }^{1}$, Dewa Made Wiharta ${ }^{2}$, Widyadi Setiawan ${ }^{3}$ \\ Program Studi Teknik Elektro, Fakultas Teknik, Universitas Udayana \\ Email: nidiahparwati@gmail.com ${ }^{1}$, wiharta@unud.ac.id ${ }^{2}$, widyadi@unud.ac.id $^{3}$
}

\begin{abstract}
ABSTRAK
Tanah longsor merupakan bencana alam yang tidak dapat dicegah. Di indonesia, frekuensi terjadinya tanah longsor masih cukup tinggi. Walaupun tidak dapat dicegah, namun upaya untuk meminimalisir kerugian yang diakibatkan oleh tanah longsor dapat dilakukan dengan memasang alat peringatan dini bahaya tanah longsor. Penelitian ini bertujuan untuk merancang early warning system menggunakan ATmega328 dengan sensor hygrometer dan sensor piezoelectric. Sistem ini memiliki tiga status yaitu aman, waspada dan awas. Persentase kelembaban tanah dan pergerakan tanah dapat dipantau melalui smartphone dan pada situs www.thingspeak.com. Sistem akan mengirim sms ketika status longsor awas.Berdasarkan pengujian yang telah dilakukan sistem yang dibuat sudah mampu mengirim data sensor ke web server ThingSpeak secara realtime, mengirim sms himbauan terkait status bahaya dan menghidupkan buzzer ketika status awas
\end{abstract}

Kata kunci: Hygrometer, Piezoelectric , Tanah longsor

\section{PENDAHULUAN}

Bencana merupakan sesuatu yang menimbulkan kesusahan, kerugian, penderitaan dan kecelakaan. Bencana dapat disebabkan oleh manusia dan juga faktor alam. Salah satu bencana yang sering terjadi di Indonesia adalah tanah longsor. Tanah longsor terjadi karena bergesernya sejumlah massa tanah dalam skala besar maupun kecil dengan pergerakan yang perlahan ataupun spontan. Faktor-faktor yang menyebabkan pergeseran tanah tersebut diantaranya adalah pengikisan/erosi, getaran, kenaikan kapasitas air dalam tanah, kemiringan lereng, curah hujan yang tinggi, dan penebangan liar tanpa melakukan reboisasi. Jenis-jenis longsor diantaranya longsor runtuhan, longsor pergerakan blok, longsor rotasi, longsor rayapan tanah, dan longsor aliran material bumi. Masingmasing jenis longsor tersebut memiliki kecepatan pergerakan tanah yang berbeda, oleh karena itu memerlukan penanganan yang berbeda.

Frekuensi terjadinya longsor di Indonesia masih cukup tinggi. Data yang dihimpun oleh Badan Nasional Penanggulangan Bencana (BNPB), selama tahun 2016 terdapat 612 bencana longsor di seluruh wilayah Indonesia. Kejadian ini meningkat sebanyak 19 persen dibandingkan tahun 2015 sekaligus menduduki peringkat kedua bencana yang sering terjadi setelah banjir (BNPB,2017) [1]. Dampak dari bencana tanah longsor yaitu rusaknya berbagai fasilitas umum seperti saluran penerangan dan telekomunikasi, warga kehilangan tempat tinggal dan adanya korban jiwa baik manusia maupun hewan ternak.

Upaya untuk meminimalisir korban jiwa dan kerugian materi yang diakibatkan oleh tanah longsor dapat dilakukan dengan memasang alat peringatan dini bahaya longsor. Terkait dengan peringatan dini bahaya longsor, dalam penelitian ini dikembangkan Rancang Bangun Sistem Peringatan Dini Bahaya Tanah Longsor dengan Sensor Hygrometer dan Piezoelectric yang diharapkan dapat memberikan informasi dini potensi longsor. Sensor hygrometer adalah alat yang digunakan untuk mendeteksi kelembaban tanah dan sensor piezoelectric adalah alat yang digunakan untuk mengukur pergeseran tanah. Sistem minimum yang digunakan pada penelitian ini dikontrol oleh mikrokontroler ATmega328.

Meskipun sudah banyak penelitian terkait detektor longsor, namun penelitian 
tersebut lebih banyak berfokus pada longsor translasi. Longsor translasi terjadi dengan ciri-ciri adanya satu blok atau lebih material bumi bergerak pada permukaan datar dengan bidang miring (WSGS, 2015) [2]. Penelitian ini meneliti jenis longsor yang berbeda, yaitu longsor jenis rayapan. Longsor rayapan merupakan longsor dengan kecepatan rendah dengan pergerakan material bumi sekitar 1.6 meter per tahun. Namun, walaupun pergerakan longsor rayapan tergolong lambat, tetap saja menimbulkan kerusakan seperti tiang listrik dan bangunan menjadi miring. Fitur penting yang dibangun dalam penelitian ini adalah bahwa data kelembaban tanah dan pergerakan tanah dapat dipantau melalui smartphone maupun personal computer yang dapat diakses oleh siapa saja.

\section{KAJIAN PUSTAKA Sensor Hygrometer}

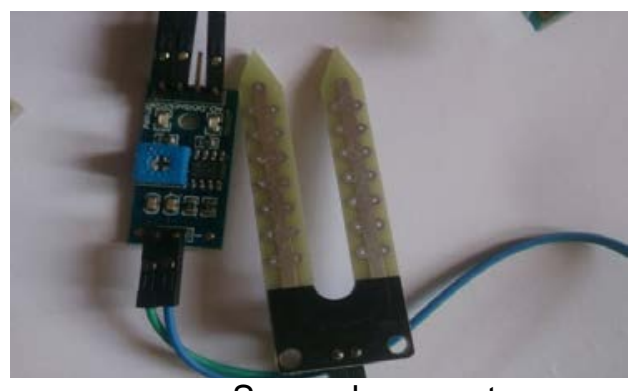

Sensor hygrometer

Gambar 1 adalah alat yang digunakan untuk mendeteksi kelembaban tanah dengan tegangan kerja 3-5 V. Sensor hygrometer ini menggunakan trimpot untuk mengatur kepekaan sensor.

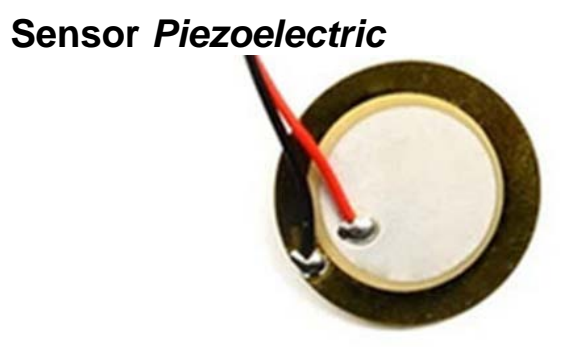

Modul Sensor Piezoelectric

Gambar 2 adalah alat yang digunakan untuk mengukur beban, tekanan, percepatan, regangan, dan lain-lain. Prinsip kerja sensor piezoelectric yaitu ketika sensor mendeteksi adanya beban, tekanan, percepatan, dan regangan, maka lapisan bahan penyusun sensor yang telah diberi tegangan akan menghasilkan gelombang akustik.Gelombang akustik ini menyebabkan perubahan tegangan.Sensor piezoelectric sering diterapkan pada microphone dan printer

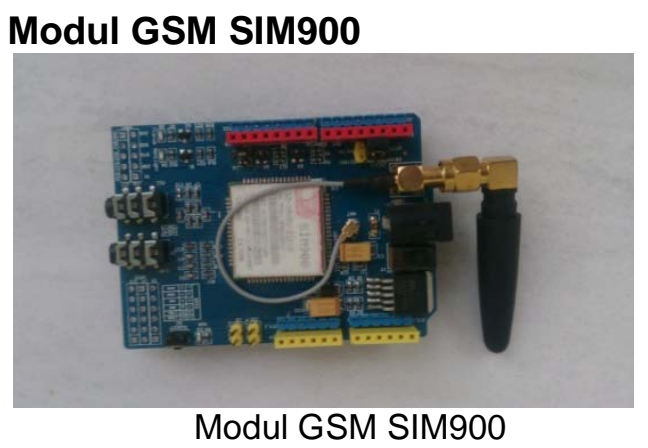

Gambar 3 adalah modul yang digunakan untuk mengirim pesan himbauan terkait status segera mengungsi ketika status awas. Melalui pin Tx dan Rx, modul GSM dapat berkomunikasi dengan mikrokontroler ATmega328 dan dikendalikan dengan perintah $A T$ command.

\section{Mikrokontroler ATmega328}

ATmega328 merupakan mikrokontroler keluarga AVR 8 bit. Yang membedakan ATmega328 dengan mikrokontroler AVR 8 bit lainnyayaitu ukuran memori, jumlah pin input/output dan fungsi peripheral seperti USART, timer, dan counter. ATmega328 Memiliki 3 buah port utama yaitu PORTB, PORTC, dan PORTD dengan jumlah total pin sebanyak 28 pin. Port tersebut dapat difungsikan sebagai input/output digital atau difungsikan sebagai periperial lainnya. ATMega328 memiliki ukuran flash memori sebesar 32KB, SRAM sebesar 2KB, dan memori EEPROM sebesar 1KB.

\section{Arduino IDE}

Software yang digunakan dalam membuat program adalah Arduino IDE (Arduino,2018)[3] yaitu software yang merupakan bawaan dari Arduino itu sendiri. Untuk menuliskan source program, compile dan upload, dapat dilakukan dengan meggunakan bahasa program $\mathrm{C}$, dengan demikian program dapat diproses ke dalam mikrokontroler Arduino ATMega 328. Software Arduino IDE dapat dijalankan pada sistem operasi windows, MAC dan linux. Pada penelitian ini menggunakan Software Arduino Uno 1.6.1. 


\section{ThingSpeak}

ThingSpeak (Thingspeak,2018) [4] merupakan layanan open source Internet of Things (IOT) yang memungkinkan pengguna untuk mengumpulkan, menganalisis dan memonitoring data dari mikrokontroler. Pada penelitian ini layanan ThingSpeak digunakan untuk menampilkan data getar dan kelembaban tanah yang dapat dipantau melalui smartphone maupun personal computer.

\section{METODOLOGI PENELITIAN}

Diagram alir diperlukan untuk membantu poses pembuatan sistem. Mulai dari study literature, perancangan perangkat keras, perancangan perangkat lunak, dan terakhir adalah proses pengujian dari alat yang telah dibuat.

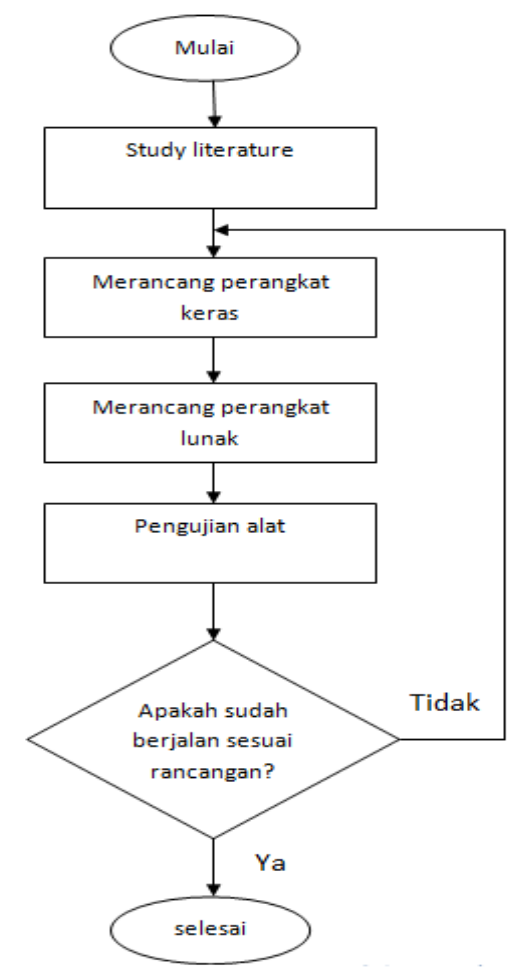

Diagram Alir Perancangan

Gambar 4 merupakan Diagram alir keseluruhan dari rancang bangun sistem peringatan dini bahaya tanah longsor dengan sensor hygrometer dan piezoelectric

\section{HASIL DAN PEMBAHASAN 4.1 Hasil}

Pada penelitian ini telah direalisasikan prototype peringatan dini bahaya tanah longsor dengan sensor hygrometer dan piezoelectric. Prototype secara keseluruhan ditunjukkan pada Gambar 5.

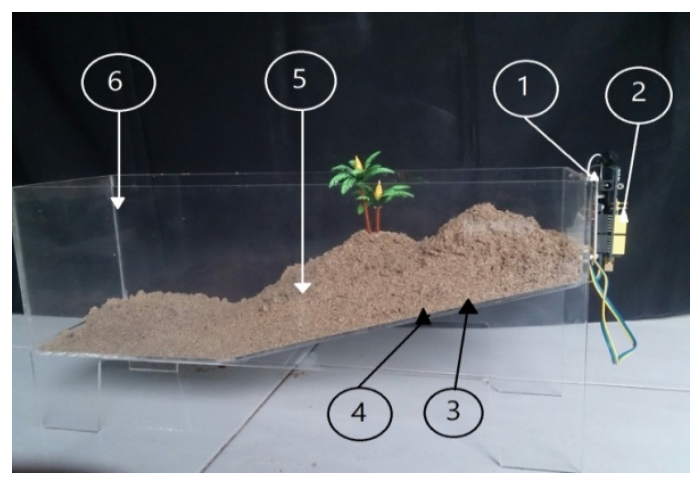

Gambar 5 Prototype Peringatan Dini Bahaya Tanah Longsor

\section{Keterangan:}

1. Board mikrokontroler

2. Modul GSM SIM900

3. Sensor hygrometer

4. Sensor piezoelectric

5. Material longsor

6. Box acrylic

\subsection{Pembahasan Pengujian Dan Pembahasan Sensor}

Pengujian sensor hygrometer dan piezoelectric bertujuan untuk mengetahui nilai output maksimal pada masing-masing sensor dan menentukan nilai sensor untuk masing-masing status bencana. Pengujian sensor hygrometer dilakukan dengan cara mengubur sensor ke dalam tanah basah. Sedangkan pengujian sensor piezoelectric dilakukan dengan cara megetuk body sensor. Setelah itu output sensor akan ditampilkan pada serial monitor arduino IDE. Tabel 1 adalah tabel hasil nilai output maksimal kedua sensor.

Tabel 1 Nilai Output Maksimal Sensor Hygrometer dan Piezoelectric

\begin{tabular}{|c|c|c|}
\hline $\begin{array}{c}\text { Kelembaban } \\
(\%)\end{array}$ & $\begin{array}{c}\text { Sensor } \\
\text { Hygrometer }\end{array}$ & $\begin{array}{c}\text { Sensor } \\
\text { Piezoelectric }\end{array}$ \\
\hline 0 & 0 & 0 \\
\hline 100 & 850 & 200 \\
\hline
\end{tabular}

Setelah nilai maksimal kedua sensor diketahui, selanjutnya nilai sensor dalam bit dikonversi ke persen (\%). Konversi nilai 
sensor dalam bit ke persen (\%) ditunjukkan pada Tabel 2 dan Tabel 3.

Tabel 2 Konversi Nilai Sensor Kelembaban Dari Bit ke Persen (\%)

\begin{tabular}{|c|c|c|}
\hline No & $\begin{array}{c}\text { Sensor } \\
\text { Hygrometer }\end{array}$ & $\begin{array}{c}\text { Kelembaban } \\
(\%)\end{array}$ \\
\hline 1 & 0 & 0 \\
\hline 2 & 85 & 10 \\
\hline 3 & 170 & 20 \\
\hline 4 & 255 & 30 \\
\hline 5 & 340 & 40 \\
\hline 6 & 425 & 50 \\
\hline 7 & 510 & 60 \\
\hline 8 & 595 & 70 \\
\hline 9 & 680 & 80 \\
\hline 10 & 765 & 90 \\
\hline 11 & 850 & 100 \\
\hline
\end{tabular}

Tabel 3 Konversi Nilai Sensor Piezoelectric Dari Bit ke Persen (\%)

\begin{tabular}{|c|c|c|}
\hline No & $\begin{array}{c}\text { Sensor } \\
\text { Piezoelectric }\end{array}$ & Getar (\%) \\
\hline 1 & 0 & 0 \\
\hline 2 & 20 & 10 \\
\hline 3 & 40 & 20 \\
\hline 4 & 60 & 30 \\
\hline 5 & 80 & 40 \\
\hline 6 & 100 & 50 \\
\hline 7 & 120 & 60 \\
\hline 8 & 140 & 70 \\
\hline 9 & 160 & 80 \\
\hline 10 & 180 & 90 \\
\hline 11 & 200 & 100 \\
\hline
\end{tabular}

Berikut ini adalah program yang digunakan untuk menguji kedua sensor.

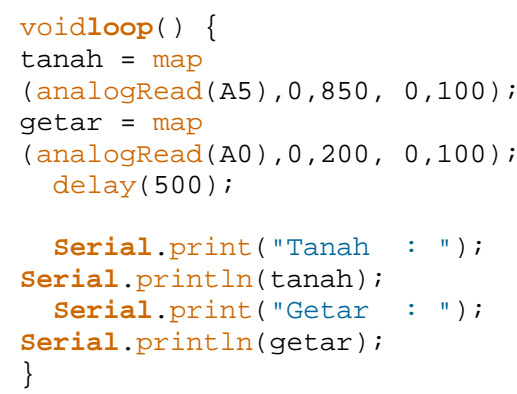

Hasil pengujian pada masing-masing status sesuai dengan koding program tersebut ditunjukkan pada Gambar 6.

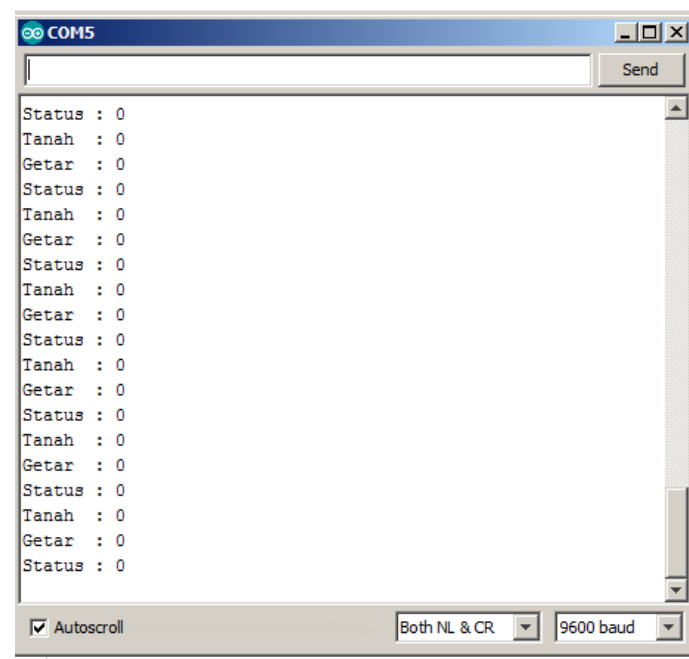

Gambar 6 Pengujian Sensor Ketika Tidak Ada Pergerakan Tanah

Gambar 6 adalah pengujian sensor dalam kondisi tidak ada pergerakan tanah. Kondisi yang sama diperoleh sampai nilai pembacaan sensor getar $<5 \%$ dan sensor kelembaban < 3.5\%. Oleh karena itu kondisi tersebut dinyatakan sebagai status aman.

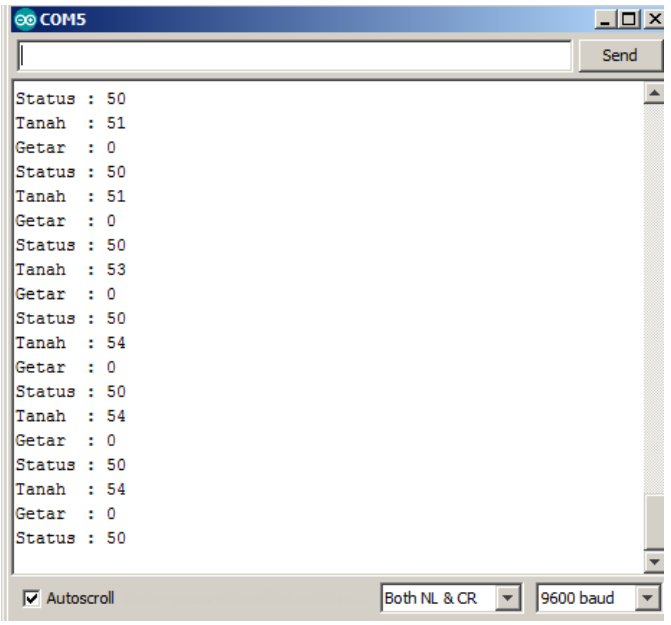

Gambar 7 Pengujian Sensor Ketika Mulai Ada Pergerakan Tanah

Gambar 7 adalah pengujian sensor dalam kondisi ketika mulai ada pergerakan tanah. Dari hasil pengamatan diperoleh bahwa tanah mulai mengalami sedikit pergerakan ketika pembacaan sensor getar $<5 \%$ dan sensor kelembaban > 3.5\%. Ketika sensor getar $>5 \%$, tanah mulai bergerak lebih cepat. Untuk itu ditentukan bahwa status waspada adalah dalam rentang sensor getar $<5 \%$ dan sensor kelembaban $>3.5 \%$. 


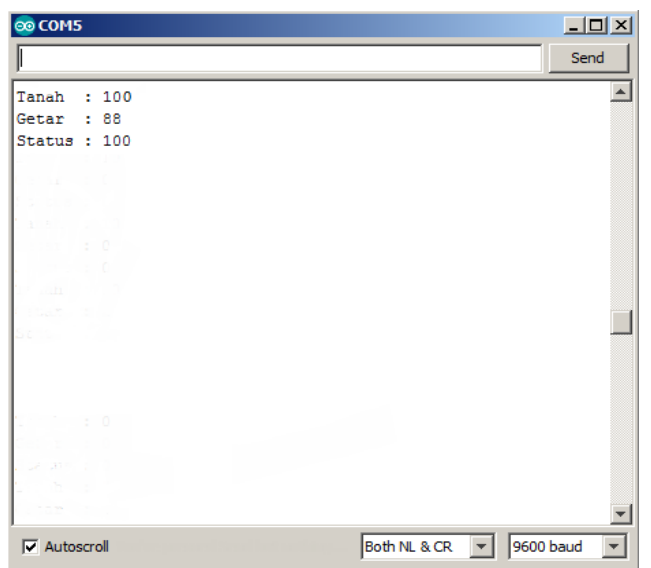

Gambar 8 Pengujian Sensor Ketika Tanah Bergerak Lebih Cepat

Gambar 8, adalah pengujian sensor dalam kondisi ketika tanah bergerak lebih cepat. Dari Hasil pengamatan diperoleh bahwa tanah bergerak lebih cepat ketika pembacaan sensor getar $>5 \%$ dan sensor kelembaban > 3.5\%. Oleh karena itu, dalam rentang nilai tersebut dinyatakan sebagai status awas.

\section{Penentuan Status Bencana}

Karena tidak ada referensi mengenai status bencana longsor, maka dilakukan pengamatan untuk menentukan status aman, waspada dan awas. Status aman adalah kondisi ketika tidak ada pergerakan tanah. Status waspada adalah kondisi ketika mulai ada pergerakan tanah. Dan status awas adalah kondisi ketika tanah bergerak lebih cepat. Berikut adalah nilai pada masing-masing status didapatkan berdasarkan pengamatan yang ditunjukkan pada Tabel 4

Pada grafik thingspeak, status aman akan ditunjukkan dengan angka 0 , status waspada ditunjukkan dengan angka 50 dan status awas ditunjukkan dengan angka 100.

\section{Pengujian Dan Pembahasan Pengiriman Data Sensor ke ThingSpeak}

Pengujian pengiriman data sensor ke thingspeak dilakukan untuk mengetahui keberhasilan data yang dikirim ke thingspeak dan memastikan apakah nilai yang tertera pada grafik thingspeak sudah sesuai dengan nilai pada Tabel 4. Pengujian dilakukan pada masing-masing status.

Tabel 4 Nilai Getar dan Nilai Kelembaban Pada Masing-Masing Status

\begin{tabular}{|c|c|c|c|c|}
\hline Tampilan pada Thingspeak & Status & Nilai Getar & Nilai kelembaban & Keterangan \\
\hline 0 & Aman & $<5 \%$ & $<3.5 \%$ & $\begin{array}{c}\text { Kondisi ketika tidak ada } \\
\text { pergerakan tanah }\end{array}$ \\
\hline 50 & Waspada & $<5 \%$ & $>3.5 \%$ & $\begin{array}{c}\text { Kondisi ketika mulai ada } \\
\text { pergerakan tanah }\end{array}$ \\
\hline 100 & Awas & $>5 \%$ & $>3.5 \%$ & $\begin{array}{c}\text { Kondisi ketika tanah } \\
\text { bergerak lebih cepat. }\end{array}$ \\
\hline
\end{tabular}

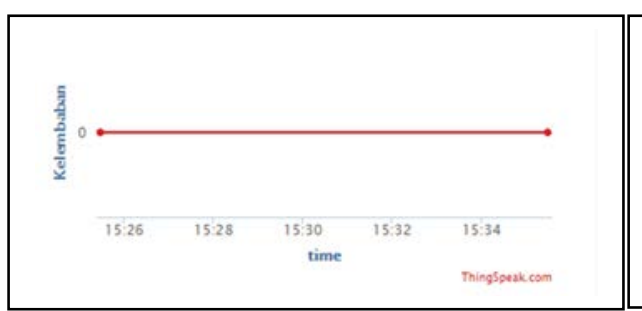

(a)

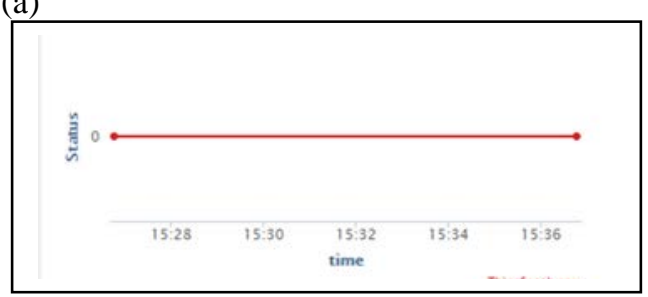

(c)

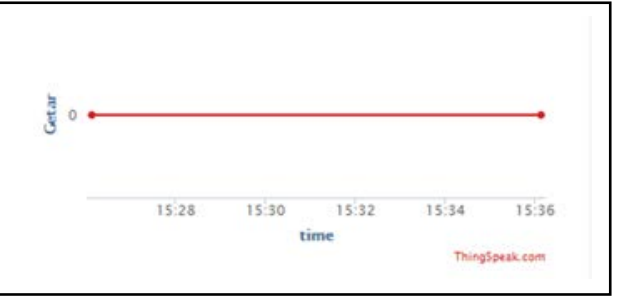

(b)

Gambar 9 Tampilan Data Sensor Saat Status Aman (a) Grafik Kelembaban (b) Grafik Getar (c) Grafik Status 


\section{Status Aman}

Status aman merupakan kondisi sejumlah massa tanah dalam skala besar maupun kecil tidak menunjukkan adanya perubahan yang signifikan. Status aman dinyatakan dengan nilai getar $<5 \%$ dan nilai kelembaban < 3.5\%. Gambar9 menunjukkan hasil pengujian pengiriman data ke thingspeak saat status aman

Berdasarkan Gambar 9, diketahui bahwa grafik kelembaban dan grafik getar bernilai 0 karena kedua sensor tidak menangkap adanya input. Dari kedua nilai tersebut, grafik status menghasilkan nilai 0 yang berarti aman. Hal ini menunjukkan bahwa hasil pengujian sudah sesuai dengan Tabel 4 yaitu status aman dinyatakan dengan nilai getar $<5 \%$ dan nilai kelembaban $<3.5 \%$.

\section{Status Waspada}

Status waspada adalah kondisi ketika mulai ada pergerakan material bumi yang disebabkan oleh hujan, gempa, maupun faktor lain. Status waspada dinyatakan dengan nilai getar $<5 \%$ dan nilai kelembaban > 3.5\%. Gambar 10 menunjukkan hasil pengujian pengiriman data ke thingspeak saat status waspada.

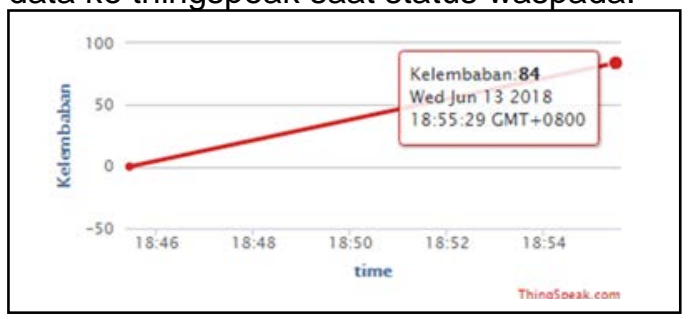

(a)

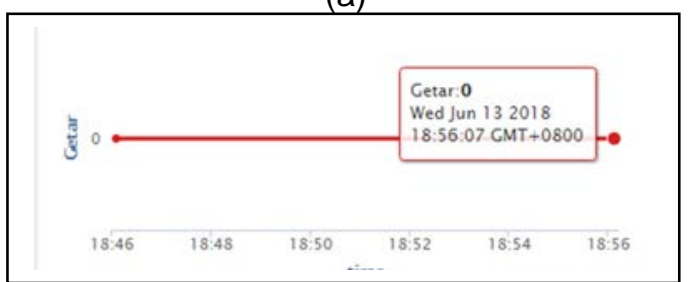

(b)

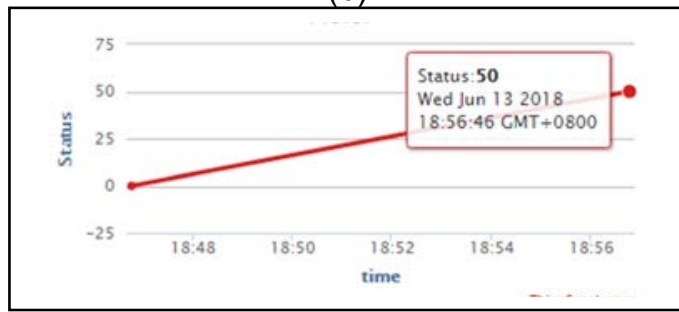

(c)

Gambar 10 Tampilan Data Sensor Saat Status Waspada (a) Grafik Kelembaban (b) Grafik Getar (c) Grafik Status
Berdasarkan Gambar 10, dapat dilihat bahwa grafik kelembaban menunjukkan adanya kelembaban yang diterima oleh sensor sebesar 84 bit. Sedangkan grafik getar tidak menunjukkan perubahan karena sensor tidak menangkap adanya input sehingga data getar adalah 0 . Dari kedua nilai tersebut diperoleh nilai 50 pada grafik status, dimana nilai 50 berarti waspada. Hal ini menunjukkan bahwa hasil pengujian sudah sesuai dengan Tabel 4 yaitu status waspada dinyatakan dengan nilai getar $<5 \%$ dan nilai kelembaban $>$ $3.5 \%$.

\section{Status Awas}

Status awas merupakan kondisi yang paling memungkinkan terjadinya longsor. Status awas dinyatakan dengan nilai getar $>5 \%$ dan nilai kelembaban sama dengan $>$ 3.5\%. Gambar 11 menunjukkan hasil pengujian pengiriman data ke thingspeak saat status awas.

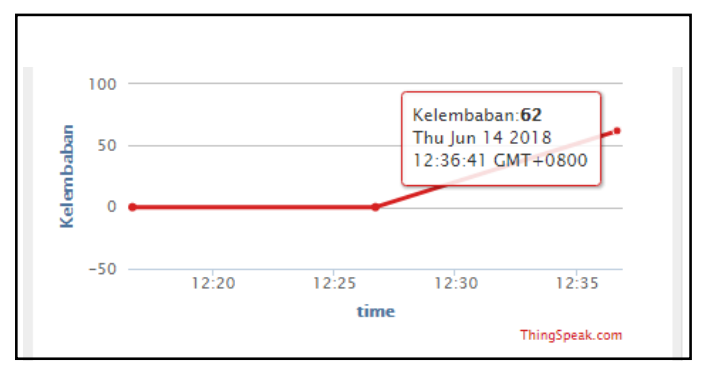

(a)

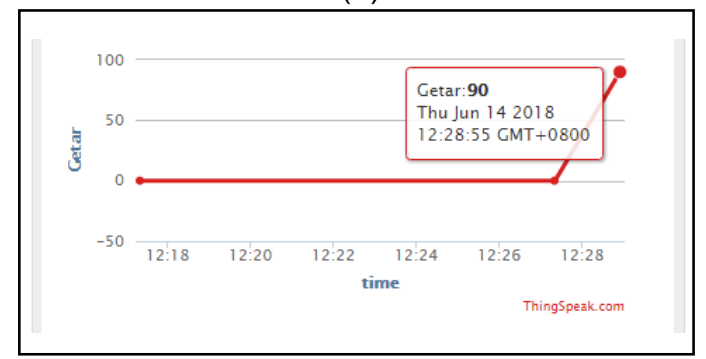

(b)

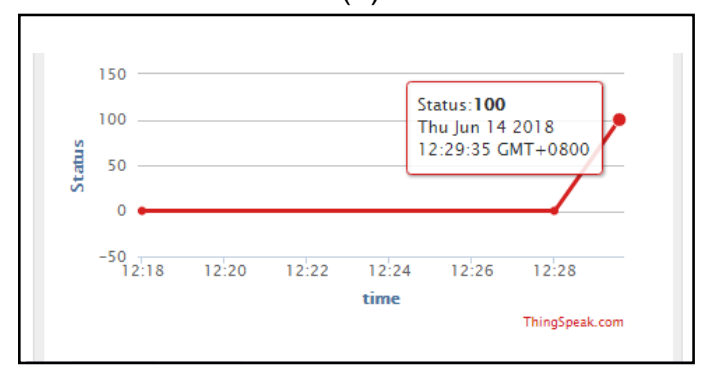

(c)

Gambar 11 Tampilan Data Sensor Saat Status Awas (a) Grafik Kelembaban (b) Grafik Getar (c) Grafik Status 
Berdasarkan Gambar 11 dapat dilihat bahwa grafik kelembaban menunjukkan adanya kelembaban yang diterima oleh sensor sebesar 62 bit. Sedangkan grafik getar menunjukkan adanya getaran yang diterima oleh sensor sebesar 90 bit. Dari kedua nilai tersebut, grafik status menghasilkan nilai 100 yang berarti status awas. Hal ini menunjukkan bahwa hasil pengujian sudah sesuai dengan Tabel 4, yaitu status awas dinyatakan dengan nilai getar $>5 \%$ dan nilai kelembaban $>35 \%$.

\section{Pengujian Dan Pembahasan Pengiriman Data Sensor Melalui SMS}

Pengujian pengiriman SMS bertujuan untuk menguji apakah device yang dibuat bisa mengirim pesan himbauan terkait status bahaya, serta memastikan data yang dikirim akurat sesuai dengan data pada thingspeak. Notifikasi SMS hanya terkirim pada saat status awas. Berikut adalah hasil pengujian yang sudah dilakukan per tanggal 14 juni 2018.

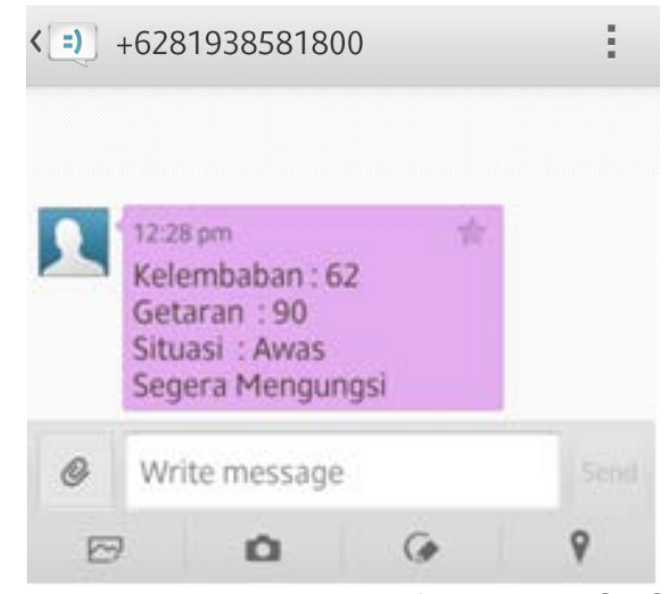

Gambar 12 Tampilan Notifikasi Pada SMS

Pada Gambar 12 terlihat bahwa nilai kelembaban dan nilai getar sudah sesuai dengan data pada thingspeak. Hal ini menunjukan bahwa himbauan untuk segera mengungsi dan pengiriman data melalui SMS sudah berhasil.

\section{PENUTUP \\ Simpulan}

Peringatan dini terkait bahaya tanah longsor bisa dibangun dengan sensor hygrometer dan sensor piezoelectric yang dikontrol dengan mikrokontroler ATmega328. Dari hasil pengamatan diperoleh bahwa status bencana tanah longsor bisa diklasifikasikan dalam tiga status yaitu: (1) Status aman dinyatakan dengan nilai getar < 5\% dan nilai kelembaban $<3.5 \%$. (2) Status waspada dinyatakan dengan nilai getar $<5 \%$ dan nilai kelembaban $>3.5 \%$, dan (3) Status awas dinyatakan dengan nilai getar $>5 \%$ dan nilai kelembaban $>3.5 \%$.

Untuk memudahkan diseminasi bencana tanah longsor bisa dilakukan dengan memanfaatkan media komunikasi dengan modul GSM SIM900. Dalam penelitian ini diseminasi data dilakukan secara realtime dengan memanfaatkan layanan SMS pada komunikasi seluler. Kondisi pergerakan tanah juga bisa dimonitor secara online melalui www.thingspeak.com.Sistem yang dibuat sudah mampu mengirim data sensor ke web server thingspeak secara realtime, mengirim sms himbauan terkait status bahaya dan menghidupkan buzzer ketika status awas

\section{Saran}

Agar alat ini dapat berfungsi lebih baik lagi, ada beberapa hal yang perlu dikembangkan diantaranya: Web server ThingSpeak bisa diganti dengan web server sendiri agar keamanan data lebih terjaga, Notifikasi sms yang hanya ke satu nomor, dapat dibuat mengirim ke lebih banyak nomor agar peringatan untuk mengungsi tersampaikan ke semua warga ditempat. Sistem yang dibuat bisa ditambahkan fungsi kalibrasi agar dapat disesuaikan dengan kondisi dan jenis tanah yang berbeda. Dan untuk mendapatkan pengukuran yang lebih akurat, jarak jangkau deteksi sensor perlu diukur untuk mengetahui area cakupan sensor.

\section{DAFTAR PUSTAKA}

[1] Badan Nasional Penanggulangan Bencana. $2017 . \quad$ Kajian Bencana. https://bnpb.go.id/ Diakses pada tanggal 5 November 2017

[2] Wyoming State Geological Survey. 2016. Landslides In Wyoming http://www.wsgs.wyo.go v/hazards/landslides Diakses pada tanggal 7 Desember 2017

[3] Arduino 2018. Arduino Software. https://www.arduino.cc/ en/Main/Software Diakses pada tanggal 18 Desember 2017 
[4] Thingspeak 2018. The Open IoT Flatform With Matlab Analtytics https://thingspeak.com/ Diakses pada tanggal 5 Februari 2018

[5] Ahmad Ridho, dkk. "Perancangan Deteksi Longsor Di Bukit Watu Buceng Dusun Ketos Desa Wonodadi Kulon", Jurnal Pengabdian LPPM Untag Surabaya, Vol.01, No.02, hal 111118, Nopember 2015

[6] Badan Meteorologi Dan Geofisika. 2018. Skala MMI. https://www.bmkg.go.id/gem pabumi/skala-mmi.bmkg Diakses pada tanggal 27 Juli 2018

[7] Dandun Widhiantoro, A.Md.T.,MT. "Purwarupa Sistem Pendeteksi Tanah Longsor Menggunakan Ultrasonik Dan Infrared Dengan Notifikasi SMS", Ejournal Kajian Teknik Elektro Vol.1 No.2 Universitas 17 Agustus 1945 Jakarta

[8] Murata. 2018. Piezoelectric Sounds

Component. https://www.murata .com/. Diakses pada tanggal 17 Juni 2018

[9] Mohamad Jamil dan Jamalun Togubu. "Implementasi Teknologi Wireless Sensor Network (WSN) Untuk Pergeseran Tanah", Jurnal Protek Vol. 03 No.2, September 2016.

[10] Sugito, dkk. "Rancang Bangun Sistem Pengukuran Pergeseran
Tanah Menggunakan Sensor Variabel Resistor", Berkala Fisika, vol 18, No.1, Januari 2015, hal 9-16

[11] Suraya dan Muhammad Andang Novianta. "Perancangan Sistem Pergeseran Tanah Menggunakan Sensor Draw Wire Berbasis Mikrokontroler Dengan Informasi SMS Gateway" , Prodising SENATEK 2015, Fakultas Teknik, Universitas Muhammadiyah Purwokerto

[12] Syarifah Mutia Bazlina, dkk. "Perancangan Prototipe Sistem Peringatan Dini Bencana Longsor Berbasis Mikrokontroler Atmega328", Jurnal Teknik Elektro, vol.2 No.1 2017

[13]U.S Geological Survey. 2004. Landslide Types And Processes https://pubs.usgs.gov /fs/2004/3072/fs-2004-3072.html Diakses pada tanggal 7 Desember 2017

[14] Sastra, Nyoman Putra, and Dewa Made Wiharta. "Environmental monitoring as an IOT application in building smart campus of Universitas Udayana." In Smart Green Technology in Electrical and Information Systems (ICSGTEIS), 2016 International Conference on, pp. 85-88. IEEE, 2016. 